\title{
Unil
}

UNIL | Université de Lausanne

Unicentre

$\mathrm{CH}-1015$ Lausanne

http://serval.unil.ch

Year : 2020

\section{Comparison of Swiss and European Risk Algorithms for Cardiovascular Prevention in Switzerland}

\author{
Beuret Hadrien
}

Beuret Hadrien, 2020, Comparison of Swiss and European Risk Algorithms for Cardiovascular Prevention in Switzerland

Originally published at : Thesis, University of Lausanne

Posted at the University of Lausanne Open Archive http://serval.unil.ch

Document URN : urn:nbn:ch:serval-BIB_97997D4DB6082

\section{Droits d'auteur}

L'Université de Lausanne attire expressément l'attention des utilisateurs sur le fait que tous les documents publiés dans l'Archive SERVAL sont protégés par le droit d'auteur, conformément à la loi fédérale sur le droit d'auteur et les droits voisins (LDA). A ce titre, il est indispensable d'obtenir le consentement préalable de l'auteur et/ou de l'éditeur avant toute utilisation d'une oeuvre ou d'une partie d'une oeuvre ne relevant pas d'une utilisation à des fins personnelles au sens de la LDA (art. 19, al. 1 lettre a). A défaut, tout contrevenant s'expose aux sanctions prévues par cette loi. Nous déclinons toute responsabilité en la matière.

\section{Copyright}

The University of Lausanne expressly draws the attention of users to the fact that all documents published in the SERVAL Archive are protected by copyright in accordance with federal law on copyright and similar rights (LDA). Accordingly it is indispensable to obtain prior consent from the author and/or publisher before any use of a work or part of a work for purposes other than personal use within the meaning of LDA (art. 19, para. 1 letter a). Failure to do so will expose offenders to the sanctions laid down by this law. We accept no liability in this respect. 


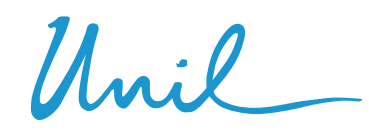

UNIL | Université de Lausanne

Faculté de biologie

et de médecine

UNIVERSITE DE LAUSANNE - FACULTE DE BIOLOGIE ET DE MEDECINE

Département de médecine - Centre Hospitalier Universitaire Vaudois (CHUV)

Service de médecine interne

Comparison of Swiss and European Risk Algorithms for Cardiovascular

Prevention in Switzerland

\section{THESE}

préparée sous la direction du Docteur Julien Vaucher

et présentée à la Faculté de biologie et de médecine de

I'Université de Lausanne pour l'obtention du grade de

DOCTEUR EN MEDECINE

par

Hadrien BEURET

Médecin diplômé de la Confédération Suisse

Originaire de Soubey (Jura) 



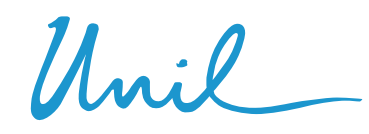

UNIL | Université de Lausanne

Faculté de biologie

et de médecine

UNIVERSITE DE LAUSANNE - FACULTE DE BIOLOGIE ET DE MEDECINE

Département de médecine - Centre Hospitalier Universitaire Vaudois (CHUV)

Service de médecine interne

Comparison of Swiss and European Risk Algorithms for Cardiovascular

Prevention in Switzerland

\section{THESE}

préparée sous la direction du Docteur Julien Vaucher

et présentée à la Faculté de biologie et de médecine de

I'Université de Lausanne pour l'obtention du grade de

DOCTEUR EN MEDECINE

par

Hadrien BEURET

Médecin diplômé de la Confédération Suisse

Originaire de Soubey (Jura) 


\section{Imprimatur}

Vu le rapport présenté par le jury d'examen, composé de

Directeur de thèse Monsieur le Docteur Julien Vaucher

Co-Directeur de thèse

Expert

Madame la Professeure Murielle Bochud

Vice-Directeur de

Monsieur le Professeur John Prior

l'Ecole doctorale

la Commission MD de l'Ecole doctorale autorise l'impression de la thèse de

\section{Monsieur Hadrien BEURET}

intitulée

Comparison of Swiss and European Risk Algorithms for Cardiovascular Prevention in Switzerland

Lausanne, le 19 mai 2020

pour Le Doyen

de la Faculté de Biologie et de Médecine

Monsieur le Professeur John Prior

Vice-Directeur de l'Ecole doctorale 


\section{Comparaison des Algorithmes de Prévention Cardiovasculaire Suisse et Européen dans une Cohorte Suisse}

Contexte : En Suisse, la prévention cardiovasculaire est basée sur des recommandations émanant de deux sociétés savantes différentes: 1) le Groupe de travail Lipides et Athérosclérose (GSLA) »; et 2) la Société Européenne de Cardiologie (ESC). Chacune fournit un score de risque cardiovasculaire (PROCAM pour le GSLA et SCORE pour l'ESC), ainsi qu'un algorithme de prise en charge, guidant les mesures de prévention en fonction du risque cardiovasculaire estimé.

But : Notre but premier était de déterminer lequel, entre l'algorithme du GSLA et celui de l'ESC, était le plus performant pour prédire la survenue d'événements cardiovasculaires athérosclérotiques (ECVA), ainsi que leur propension respective à recommander la prescription de statines dans la population suisse. Notre deuxième but était de valider pour la Suisse les scores de risque du GSLA et de l'ESC, couramment utilisés en prévention primaire.

Méthode : Les données sont basées sur une étude populationnelle prospective, la cohorte «CoLaus ». L'échantillon initial comprenait 6'733 personnes, âgées de 35 à 75 ans (54\% de femmes), qui furent suivies durant 10 ans. Nous avons calculé les performances de discrimination et de calibration des algorithmes du GSLA et de l'ESC, et ainsi déterminé leurs capacités à prédire la survenue d'événements cardiovasculaires.

Résultats : Des 6'733 participants de l'échantillon initial, 5'529 avaient des données complètes et furent inclus dans nos analyses. L’âge moyen (déviation standard, DS) était de 52.4 (10.6) ans. Durant un suivi moyen (DS) de 10.2 (1.7) ans, 370 (6.7\%) participants présentèrent un ECVA. La sensibilité des algorithmes du GSLA et de l'ESC pour la prédiction d'ECVA étaient respectivement de 51.6\% (IC 95\%, 46.4-56.8) et de 58.6\% (53.4-63.7). Les performances de discrimination et de calibration étaient similaires entre les algorithmes du GSLA et de l'ESC, avec des valeurs d'air sous la courbe de 0.78 (95\% CI, 0.76-0.80) et de 0.79 (0.76-0.81), et des scores de Brier de 0.059 et de 0.041, respectivement. Parmi les 370 individus ayant présentés un ECVA, seulement 278 (75\%) étaient éligibles pour un traitement par statine au début du suivi. Les performances prédictives des scores de risque du GSLA et de l'ESC étaient également similaires et bonnes, validant leur usage pour la population suisse en prévention cardiovasculaire primaire.

Conclusion : Les algorithmes du GSLA et de l'ESC présentent des facultés similaires pour prédire la survenue d'événements cardiovasculaires en Suisse. Un quart des événements cardiovasculaires ont lieu chez des personnes identifiées à bas risque selon les recommandations actuelles, soulignant le besoin de développer des méthodes complémentaires pour améliorer les stratégies de prévention cardiovasculaire. 



\section{Comparison of Swiss and European risk algorithms for cardiovascular prevention in Switzerland}

\author{
Hadrien Beuret', Nadine Hausler', David Nanchen', \\ Marie Méan ${ }^{1,3}$, Pedro Marques-Vidal ${ }^{1,3}$ and Julien Vaucher ${ }^{1,3}$
}

European Journal of Preventive Cardiology 0(00) I-9

(C) The European Society of Cardiology 2020

Article reuse guidelines: sagepub.com/journals-permissions DOI: 10.1 I 77/2047487320906305 journals.sagepub.com/home/cpr

(SSAGE

\begin{abstract}
Background: In Switzerland, two distinct algorithms are recommended for cardiovascular prevention: (a) Arbeitsgruppe Lipide und Atherosklerose (AGLA); and (b) European Society of Cardiology (ESC). We validated and determined which algorithm better predicts incident atherosclerotic cardiovascular disease and assessed statin eligibility in Switzerland.

Design: A prospective population-based cohort.

Methods: We employed longitudinal data of the CoLaus study involving 6733 individuals, aged 35-75 years, with a I0-year follow-up. Using discrimination and calibration, we evaluated the predictive performance of the AGLA and ESC algorithms for the prediction of atherosclerotic cardiovascular disease.

Results: From the 6733 initial participants, 5529 were analysed with complete baseline and follow-up data. Mean age (SD) was 52.4 (10.6) years and 54\% were women. During an average follow-up (SD) of 10.2 years (I.7), 370 (6.7\%) participants developed an incident atherosclerotic cardiovascular disease. The sensitivity of AGLA and ESC algorithms to predict atherosclerotic cardiovascular disease was $51.6 \%$ (95\% confidence interval $(\mathrm{Cl})$ 46.4-56.8) and 58.6\% (53.4-63.7), respectively. Discrimination and calibration were similar between the AGLA and ESC algorithms, with area under the receiver operating characteristic curve values of $0.78(95 \% \mathrm{Cl} 0.76-0.80)$ and $0.79(0.76-0.8 \mathrm{I})$, and Brier scores of 0.059 and $0.04 \mathrm{I}$, respectively. Among 370 individuals developing incident atherosclerotic cardiovascular disease, only 278 (75\%) were eligible for statin therapy at baseline, including 210 (57\%) according to both algorithms, 4 (I\%) to AGLA only and 64 (I7\%) to ESC only.

Conclusion: AGLA and ESC algorithms presented similar accuracy to predict atherosclerotic cardiovascular disease in Switzerland. A quarter of adults developing atherosclerotic cardiovascular disease were not identified by preventive algorithms to be eligible for statin therapy.
\end{abstract}

\title{
Keywords
}

Cardiovascular, prevention, risk score, myocardial infarction, guidelines, Switzerland

Received 2 October 2019; accepted 24 January 2020

\section{Introduction}

Cardiovascular disease (CVD) is the leading cause of death worldwide, accounting for more than 17 million deaths annually. ${ }^{1}$ In Switzerland, CVD also represents a health and economic burden, with about one third of all deaths attributable to $\mathrm{CVD}, 2,3$ and annual direct costs corresponding to $16 \%$ of total health expenditures. $^{2,4}$

Prevention of CVD is based on the use of different cardiovascular risk scores that were developed to assess the cumulative effect of cardiovascular risk factors.

\footnotetext{
'Service of Internal Medicine, Lausanne University Hospital, Switzerland ${ }^{2}$ Center for Primary Care and Public Health (Unisanté), University of Lausanne, Switzerland

${ }^{3}$ Faculty of Biology and Medecine, University of Lausanne, Switzerland

\section{Corresponding author:}

Hadrien Beuret, Department of Medicine, Lausanne University Hospital (CHUV), Rue du Bugnon 46, I0II Lausanne, Switzerland.

Email: hadrien.beuret@gmail.com
} 

These scores are recommended to identify patients who would benefit the most from preventive measures, including the use of statins. ${ }^{5-13}$ In Switzerland, cardiovascular prevention is based on two different guidelines: (a) the International Atherosclerosis Society guidelines (IAS), adopted by the Swiss Atherosclerosis Association (in German Arbeitsgruppe Lipide und Atherosklerose; AGLA); ${ }^{6,7,14}$ and (b) the 2016 guidelines of the European Society of Cardiology (ESC) ${ }^{5,10,15}$ Both guidelines propose risk algorithms and corresponding risk scores, using the AGLA score (based on the PROCAM score recalibrated for Switzerland) and the Systematic COronary Risk Estimation (ESC-SCORE), recalibrated for Switzerland, respectively (see Supplementary Table 1). Algorithms allow risk prediction in all patients, including those at very high risk (see Supplementary Figures 1 and 2). It is noteworthy that the AGLA and ESC algorithms differ in risk factors or thresholds of risk factors for identifying individuals at high or very high cardiovascular risk. Furthermore, the AGLA score predicts fatal and nonfatal incident coronary events whereas the ESC-SCORE estimates fatal CVD events (see Supplementary Table 1). Currently, it remains unknown which of the two algorithms and scores perform best in Switzerland. Establishing which one has a better predictive accuracy is important because implementation of preventive algorithms can greatly impact the incidence of CVD as well as the number of drugs used at large scale.

Using data of a prospective and population-based Swiss cohort, the CoLaus study, ${ }^{16}$ our first aim was to compare AGLA and ESC algorithms and validate AGLA and ESC risk prediction models (i.e. AGLA score and ESC-SCORE) for the estimation of cardiovascular risk. Second, we compared statin eligibility according to the AGLA and ESC risk algorithms, based on participants' cardiovascular risk profile and low-density lipoprotein (LDL) cholesterol levels.

\section{Methods}

\section{Study population}

The CoLaus study (www.colaus-psycolaus.ch) is a Swiss population-based prospective cohort. ${ }^{16}$ Between 2003 and 2006, 6733 subjects (age range 35-75 years, $54 \%$ women) were recruited from a random sample of the population of Lausanne, located in the Frenchspeaking part of Switzerland. The participation rate amounted to $41 \%$. The study was approved by the institutional ethics committee of the University of Lausanne and all participants provided written informed consent. Participants were invited to attend the outpatient clinic at the University Hospital of Lausanne in the morning after an overnight fasting for baseline clinical assessment, questionnaire completion and blood sample collection. Periodic surveys of the whole cohort were conducted over a 13-year follow-up. Relevant medical records of participants who declared to have presented with a CVD and/or CVD-related procedure during their lifetime were collected. Information on cause of death was also prospectively collected during the study period (see clinical data collection in the Supplementary material).

\section{Algorithms analysis}

The AGLA and ESC risk algorithms are detailed in Supplementary Figures 1 and 2. ${ }^{10,12}$

Participant selection. Participants were eligible for analysis if complete information regarding variables of interest (such as blood pressure, lipid and glycaemic values, or smoking status) were available. Furthermore, those refusing to partake in the 10-year follow-up were excluded from analysis (see Supplementary Figure 3).

Outcomes and adjudication of cardiovascular events. As the AGLA and ESC algorithms were designed to predict different cardiovascular outcomes (see Supplementary Table 1), the prediction performance of the two algorithms was compared using a common set of clinical cardiovascular outcomes, namely atherosclerotic cardiovascular disease (ASCVD), as already performed ${ }^{17}$ and recommended by the 2019 American College of Cardiology (ACC)/American Heart Association (AHA) cardiovascular preventive guidelines. ${ }^{9,18,19}$ We defined incident ASCVD as an episode of: (a) acute myocardial infarction; (b) sudden cardiac death; (c) symptomatic coronary artery disease with greater than $50 \%$ stenosis (treated by percutaneous coronary intervention or coronary artery bypass graft); and (d) fatal and non-fatal ischaemic stroke (including transient ischaemic attack). Peripheral artery disease was not included in ASCVD as this outcome was not collected in the CoLaus study.

The occurrence of an incident ASCVD was prospectively collected during the follow-up period. Participants experiencing an ASCVD were censored for the rest of the study period, preventing double counting of participants developing additional ASCVD. All cardiovascular events were independently adjudicated based on largely established recommendations and definitions (see Supplementary material). Myocardial infarction was adjudicated by two independent cardiologists, stroke by one neurologist, and deaths by two internists.

\section{Statistical analysis}

Participants' characteristics were described according to incident ASCVD. Categorical variables were 

summarised as number of subjects with column percentages, and continuous variables as means with standard deviation (SD). Pearson chi-square (for categorical variables) or analysis of variance (ANOVA) (for continuous variables) were used to evaluate differences in subjects' baseline characteristics according to the occurrence of ASCVD.

Performance of risk algorithms. To examine performance of the whole AGLA and ESC algorithms, we included people at high and very high cardiovascular risk at baseline, comprising those with pre-existing cardiovascular disease (CVD) or equivalent (see Supplementary Table 1 and Supplementary Figures 1 and 2). This approach holds the potential to represent a better assessment of the entire risk algorithms and of their public health impact.

We assessed the predictive accuracy of the AGLA and ESC algorithms to assign individuals who developed ASCVD correctly into the high/very high risk category, with regard to low/intermediate categories of risk. For individuals requiring a risk estimation based on the computation of score (i.e. without prevalent ASCVD or equivalent condition; see Supplementary Figures 1 and 2), we systematically used recalibrated versions of the AGLA score and ESC-SCORE. ${ }^{5-7,14,15}$ Discrimination and calibration were computed. Discrimination was expressed as area under the receiver operating characteristic (AUROC) curve and tested how well both algorithms distinguished high/very high risk subjects from those at low and intermediate risk. Calibration refers to the agreement between the predicted and observed rate of ASCVD and was assessed by the Brier score and Hosmer-Lemeshow statistic. In addition, goodness of fit was assessed with Akaike information criterion (AIC) and Bayesian information criterion (BIC). We derived calibration plots of the AGLA and ESC algorithms from Cox prediction models (using Stata command 'stmp2', fitting flexible parametric survival models), with partition of participants into 10 deciles of risk. Calibration plots were drawn using Stata command 'pmcalplot'.

As transient ischaemic attacks, not necessarily related to atherosclerosis, represented $41 \%$ of ischaemic strokes, we conducted an additional test by removing them from the analysis. We also performed a sensitivity analysis by excluding participants under statin therapy at baseline and reaching LDL-cholesterol targets.

Risk prediction model analysis. We additionally validated the AGLA and ESC risk prediction models (i.e. AGLA score and ESC-SCORE) using each score-specific cardiovascular outcome (i.e. 10-year risk of major coronary events and cardiovascular death, respectively) after the exclusion of high and very high risk individuals (see Supplementary Figures 1, 2 and 3). Detailed risk prediction model analysis is described in the Supplementary material.

Eligibility for statin therapy. We determined the number of participants eligible for statin treatment according to the AGLA and ESC algorithms, based on cardiovascular risk estimation and LDL-cholesterol levels. ${ }^{10,12}$ Participants were considered as eligible for statin therapy when LDL-cholesterol levels were equal to or higher than the recommended targets for each category of risk (see Supplementary Figures 1 and 2). ${ }^{10,12}$ Overlap between eligibility for statin therapy and incident ASCVD was presented as a Venn diagram. It is noteworthy that treating physicians were not implicated in any step of the study and the prescription of lipid-lowering therapy was left to their discretion.

All statistical analyses were performed using Stata 15.1 (Stata Corp, College Station, TX, USA).

\section{Results}

From the 6733 participants of the initial CoLaus study, $166(2.5 \%)$ were excluded because of missing information on variables of interest, and $1038(15.4 \%)$ refused to partake in the 10-year follow-up (see Supplementary Figure 3). Thus, 5529 participants (54.3\% women) were available for the analyses.

The mean age of participants was 52.4 years (SD 10.6) and the mean follow-up was 10.2 years (SD 1.7) (Table 1). A total of $511(9.2 \%)$ participants were on statin therapy at baseline and $166(2.9 \%)$ had prior ASCVD. The AGLA and ESC algorithms, respectively, classified $19.3 \%$ and $21.4 \%$ of participants into the high or very high risk categories (Table 2).

During the 10.2 years follow-up, $370(6.7 \%)$ participants developed an incident ASCVD, comprising 94 acute myocardial infarctions or sudden cardiac deaths, 151 symptomatic coronary artery diseases treated by revascularisation, 125 fatal and non-fatal ischaemic strokes, including 51 transient ischaemic attacks. Among the 222 participants who died during the study period, $27(12 \%)$ of them died from ASCVD. Individuals who developed ASCVD were on average 10 years older, more likely to be men, have diabetes and be a smoker, and had higher blood pressure compared with participants without incident ASCVD (Table 1).

\section{Performance of risk algorithms $(n=5529)$}

Sensitivity of the AGLA and ESC algorithms to predict ASCVD were $51.6 \%$ (95\% confidence interval (CI) 46.4-56.8) and 58.6\% (95\% CI 53.4-63.7), respectively. The negative predictive values $(95 \% \mathrm{CI})$ were $96.0 \%$ 

Table I. Participant characteristics at baseline, in risk algorithm analysis, by incident ASCVD $(\mathrm{n}=5529)$.

\begin{tabular}{|c|c|c|c|c|}
\hline & \multicolumn{4}{|c|}{ Incident ASCVD } \\
\hline & All & No & Yes & $P$ value \\
\hline$N(\%)$ & 5529 & $5159(93.3)$ & $370(6.7)$ & \\
\hline Age (years) & $52.4 \pm 10.6$ & $51.8 \pm 10.4$ & $61.1 \pm 9.6$ & $<0.001$ \\
\hline Male & $2526(45.7 \%)$ & $2274(44.1 \%)$ & 252 (68.1\%) & $<0.001$ \\
\hline Parental history of MI & $308(5.6 \%)$ & $283(5.5 \%)$ & $25(6.9 \%)$ & 0.303 \\
\hline Smoking status & & & & $<0.001$ \\
\hline Never & $2262(40.9 \%)$ & $2162(41.9 \%)$ & 100 (27.0\%) & \\
\hline Former & $1836(33.2 \%)$ & 1677 (32.5\%) & 159 (43.0\%) & \\
\hline Current & $|43|$ (25.9\%) & $1320(25.6 \%)$ & III (30.0\%) & \\
\hline \multicolumn{5}{|l|}{ Blood pressure $(\mathrm{mm} \mathrm{Hg})$} \\
\hline Systolic & $127.2 \pm 17.6$ & $126.4 \pm 17.2$ & $139.3 \pm 19.1$ & $<0.001$ \\
\hline Diastolic & $79.0 \pm 10.8$ & $78.7 \pm 10.7$ & $82.9 \pm 11.8$ & $<0.001$ \\
\hline \multicolumn{5}{|l|}{ Lipids (mmol/L) } \\
\hline Total cholesterol & $5.5 \pm 1.0$ & $5.5 \pm 1.0$ & $5.6 \pm 1.0$ & 0.394 \\
\hline HDL-cholesterol & $\mathrm{I} .6 \pm 0.4$ & $\mathrm{I} .7 \pm 0.4$ & $\mathrm{I} .5 \pm 0.4$ & $<0.001$ \\
\hline LDL-cholesterol & $3.3 \pm 0.9$ & $3.3 \pm 0.9$ & $3.4 \pm 0.9$ & 0.047 \\
\hline Triglycerides & $1.3 \pm 0.7$ & $1.3 \pm 0.7$ & $1.6 \pm 0.8$ & $<0.001$ \\
\hline Glucose (mmol/L) & $5.5 \pm 1.0$ & $5.5 \pm 0.9$ & $6.0 \pm 1.8$ & $<0.001$ \\
\hline Diabetes mellitus (\%) & $389(7.0 \%)$ & $316(6.1 \%)$ & 73 (19.7\%) & $<0.001$ \\
\hline eGFR (CKD-EPI) $\left(\mathrm{ml} / \mathrm{min} / \mathrm{l} .73 \mathrm{~m}^{2}\right)$ & $85.7 \pm 15.0$ & $86.1 \pm 14.9$ & $80.2 \pm 16.1$ & $<0.001$ \\
\hline $\begin{array}{l}\text { Prevalent chronic kidney disease } \\
\qquad\left(\mathrm{eGFR}<60 \mathrm{ml} / \mathrm{min} / \mathrm{l} .73 \mathrm{~m}^{2}\right)\end{array}$ & $228(4.1 \%)$ & $196(3.8 \%)$ & $32(8.7 \%)$ & $<0.00$ I \\
\hline Prevalent ASCVD & $162(2.9 \%)$ & $92(1.8 \%)$ & $70(18.9 \%)$ & $<0.001$ \\
\hline Statin therapy & $5 I I(9.2)$ & 406 (7.9\%) & 105 (28.4\%) & $<0.001$ \\
\hline
\end{tabular}

Results express the number of participants (\%) or mean \pm SD. Percentages are expressed by row. $P$ values were derived using Pearson chi-square or analysis of variance when appropriate.

ASCVD: atherosclerotic cardiovascular disease; MI: myocardial infarction; HDL: high-density lipoprotein; LDL: low-density lipoprotein; eGFR: estimated glomerular filtration rate; CKD-EPI: Chronic Kidney Disease Epidemiology Collaboration equation; SD: standard deviation.

Table 2. Distribution of risk categories at baseline in risk algorithm analysis, by incident ASCVD.

\begin{tabular}{|c|c|c|c|}
\hline \multirow[b]{2}{*}{ Risk categories } & \multirow[b]{2}{*}{ Total } & \multicolumn{2}{|l|}{ ASCVD } \\
\hline & & No & Yes \\
\hline$N$ & $5529(100 \%)$ & $5159(93.3 \%)$ & 370 (6.7\%) \\
\hline \multicolumn{4}{|l|}{ AGLA } \\
\hline Low $(<10 \%)$ & $4229(76.5 \%)$ & $4087(96.6 \%)$ & 142 (3.4\%) \\
\hline Intermediate $(\geq 10$ to $<20 \%)$ & $231(4.2 \%)$ & $194(84.0 \%)$ & $37(16.0 \%)$ \\
\hline High ( $\geq 20 \%)$ & $550(9.9 \%)$ & $486(88.4 \%)$ & $64(11.6 \%)$ \\
\hline Very high & $519(9.4 \%)$ & $392(75.5 \%)$ & 127 (24.5\%) \\
\hline \multicolumn{4}{|l|}{ ESC } \\
\hline Low $(<1 \%)$ & $3190(57.7 \%)$ & 3134 (98.2\%) & $56(1.8 \%)$ \\
\hline Intermediate $(\geq \mid$ to $<5 \%)$ & II 53 (20.9\%) & $1056(91.6 \%)$ & 97 (8.4\%) \\
\hline High (5 to $<10 \%)$ & $592(10.7 \%)$ & $522(88.2 \%)$ & 70 (II.8\%) \\
\hline Very high ( $\geq 10 \%)$ & 594 (10.7\%) & 447 (75.3\%) & 147 (24.7\%) \\
\hline
\end{tabular}

Individuals were classified into four risk categories according to the predicted 10-year risk of major coronary event for the AGLA algorithm and cardiovascular death for the ESC algorithm.

High and very high risk criteria are detailed in Supplementary Figures I and 2.

ASCVD: atherosclerotic cardiovascular disease; AGLA: Arbeitsgruppe Lipide und Atherosklerose; ESC: European Society of Cardiology. 

Table 3. Performance of the AGLA and ESC risk algorithms to identify incident ASCVD $(n=5529)$.

\begin{tabular}{|c|c|c|}
\hline & AGLA (95\% Cl) & ESC $(95 \% \mathrm{Cl})$ \\
\hline Sensitivity & $51.6 \%(46.4-56.8)$ & $58.6 \%(53.4-63.7)$ \\
\hline Specificity & $83.0 \%(81.9-84.0)$ & $81.2 \%(80.1-82.3)$ \\
\hline Positive predictive value & $17.9 \%(15.6-20.3)$ & $18.3 \%(16.1-20.6)$ \\
\hline Negative predictive value & $96.0 \%(95.4-96.5)$ & $96.5 \%(95.9-97.0)$ \\
\hline \multicolumn{3}{|l|}{ Discrimination } \\
\hline AUROC & $0.78(0.76-0.80)$ & $0.79(0.76-0.8 \mathrm{I})$ \\
\hline \multicolumn{3}{|l|}{ Calibration } \\
\hline Brier & 0.059 & 0.041 \\
\hline Hosmer-Lemeshow ( $P$ value) & $<0.001$ & $<0.001$ \\
\hline \multicolumn{3}{|l|}{ Model fit } \\
\hline AIC & 5813 & 5763 \\
\hline $\mathrm{BIC}$ & 5820 & 5770 \\
\hline
\end{tabular}

The AGLA and ESC risk algorithms were dichotomised into high/very high versus low/intermediate categories of risk. ASCVD: atherosclerotic cardiovascular disease; AGLA: Arbeitsgruppe Lipide und Atherosklerose score; ESC: European Society of Cardiology; Cl: confidence interval; AUROC: area under the receiver operating characteristic; AIC: Akaike information criterion; BIC: Bayesian information criterion.

(95.4-96.5) for AGLA and 96.5\% (95.9-97.0) for ESC (Table 3). Discrimination was comparable for the AGLA and ESC algorithms, with AUROC $(95 \%$ CI) of $0.78(0.76-0.80)$ and $0.79(0.76-0.81)$ (see Table 3 and Supplementary Figure 4).

Calibration of the AGLA and ESC algorithms was also comparable with Brier scores of 0,059 and 0,041 for AGLA and ESC, respectively (Table 3). The Hosmer-Lemeshow statistic showed $P$ values of less than 0.001 for both algorithms. For both AGLA and ESC algorithms, calibrations plots showed a tendency to overpredict ASCVD in the lower deciles of risk, and an underprediction in intermediate to high deciles of risk (Figure 1).

The predictive performances of the AGLA and ESC algorithms remained consistent after removing transient ischemic attacks from the analysis (see Supplementary Table 2). The results also remained similar after the exclusion of participants under statin therapy at baseline and reaching LDL-cholesterol targets (see Supplementary Table 3).

\section{Risk prediction models analysis $(n=4254$ for AGLA score and 4479 for ESC-SCORE)}

Patient characteristics and distribution of risk categories for the risk prediction model analysis are presented in Supplementary Tables 4 and 5. The AGLA score and ESC-SCORE presented valid predictive performances with very high negative predictive values $(99.1 \%$ and $99.8 \%$, respectively) and good discrimination (AUROC, 0.80 and 0.87 , respectively) (see Supplementary Table 6). The ESC-SCORE presented a marginally higher discrimination and sensitivity for its specific outcome (CVD death).

\section{Eligibility for statins $(n=5529)$}

According to the AGLA and ESC algorithms, 1206 $(21.8 \%)$ and 1917 (34.7\%) participants were eligible for statin therapy, respectively. There was a substantial overlap between the AGLA and ESC algorithms, with 1074 participants eligible for statins according to both algorithms (Figure 2). Concerning the 370 individuals who developed ASCVD, 210 (57\%) were eligible for statins according to both algorithms, 274 (74\%) according to the ESC algorithm, $214(58 \%)$ according to the AGLA algorithm. However, 92 (25\%) adults who developed ASCVD were not eligible for statins according to the algorithms.

\section{Discussion}

Using a contemporary population-based cohort with a 10-year follow-up, our findings showed that the AGLA and ESC algorithms had similar accuracy to predict a 10year risk of ASCVD in the Swiss population. We also validated the AGLA and ESC risk prediction models in Switzerland (i.e. AGLA and ESC scores) for cardiovascular primary prevention. Full compliance with algorithms for statin therapy would result in a higher number of statin prescriptions based on the ESC risk algorithm compared to AGLA's. However, neither of the two risk algorithms advocated statin use for a quarter of adults who developed ASCVD. This implied that cardiovascular prevention should be refined, through the use 



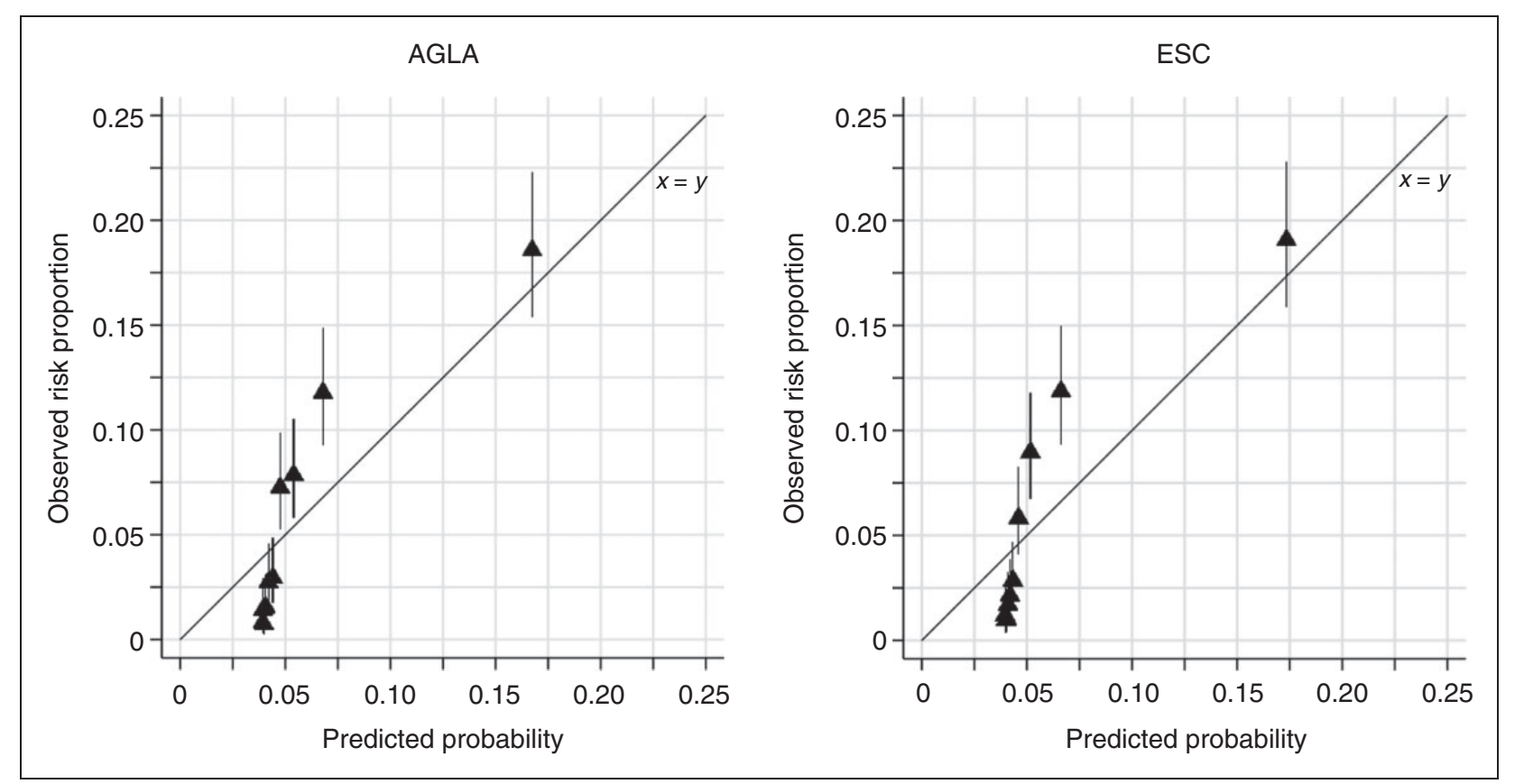

Figure I. Predicted and observed ASCVD by algorithms. Calibration plots of cardiovascular risk score-specific Cox prediction model in the algorithms analysis $(n=5529)$. Observed ASCVD in the algorithms analysis was calculated using Kaplan-Meier estimates. Participants are divided into 10 deciles of risk represented by triangles. Vertical bars indicate $95 \%$ confidence intervals. ASCVD: atherosclerotic cardiovascular disease; AGLA: Arbeitsgruppe Lipide und Atherosklerose score; ESC: European Society of Cardiology.

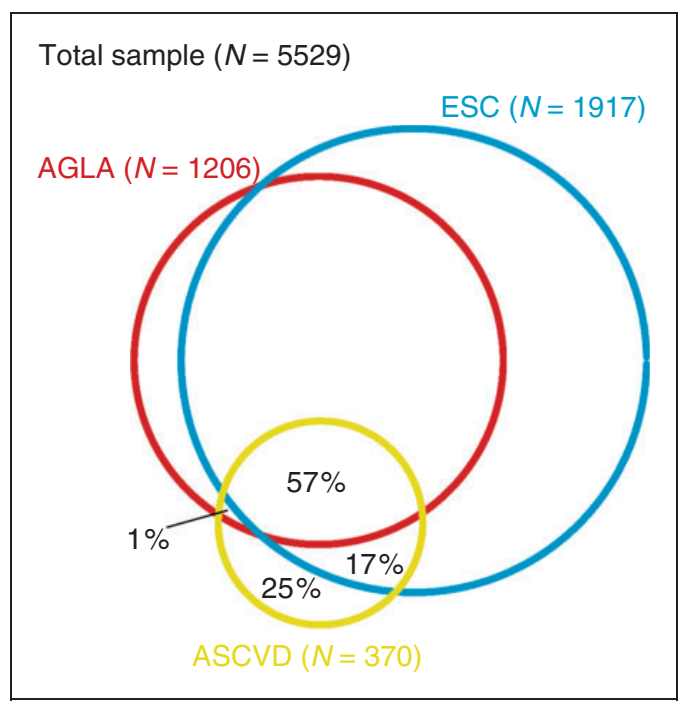

Figure 2. Statin eligibility according to the AGLA and ESC risk algorithms and incident ASCVD. The red and blue circles represent the proportional number of participants eligible to statin according to the AGLA and ESC algorithms, respectively. The yellow circle represents the participants who developed an ASCVD during the 10-year follow-up. ASCVD: atherosclerotic cardiovascular disease; AGLA: Arbeitsgruppe Lipide und Atherosklerose; ESC: European Society of Cardiology. of complementary approaches (for example, genomewide polygenic genetic risk scores or blood markers, such as lipoprotein (a)).

In Switzerland, cardiovascular prevention is based on the AGLA and ESC algorithms and their corresponding risk scores (AGLA score and ESC-SCORE). These scores have been developed in several European populations and recalibrated for Switzerland. 5-7,10,14,15 Switzerland is considered as a low cardiovascular risk country, with a prevalence of cardiovascular risk factors and disease rates similar to France, Italy, Germany, Spain, Portugal, the United Kingdom and The Netherlands. ${ }^{20,21}$ Our results showed that both algorithms were comparable and that the AGLA score and ESC-SCORE are valid for use in Switzerland. Previous studies, ${ }^{8,22}$ comparing the ESCSCORE in different European populations, have shown similar discrimination ability as in our study, with AUROC values ranging from 0.65 to 0.85 , compared to $0.87(95 \%$ CI $0.81-0.94)$ in our study. For the PROCAM score (used to derive the Swiss AGLA score), AUROCs were lower, ranging from 0.61 to 0.74 in European populations, ${ }^{8,22}$ compared to 0.80 (95\% CI $0.74-0.86)$ in our Swiss population. Overall, our results also confirmed findings from a recent 

meta-analysis showing that the performance of scores can be equalised after adequate recalibration. ${ }^{17}$

Only a third of individuals experiencing major coronary events or dying from cardiovascular causes were classified at high or very high risk according to the AGLA-score and ESC-SCORE, respectively. Another Swiss study found similar results by retrospectively assessing the risk estimation and statin eligibility among 3172 patients hospitalised for a first episode of acute coronary syndrome. ${ }^{23}$ Only $35 \%$ and $37 \%$ of subjects were identified as high risk according to the AGLA score and ESC-SCORE, respectively. Furthermore, we reported that $22 \%$ and $35 \%$ of participants would be eligible for statin treatment according to the AGLA and ESC algorithms, which is very close to the results found in a recent European meta-analysis of existing cardiovascular guidelines. ${ }^{17}$ However, we found that among the 370 individuals who developed an incident ASCVD over the 10-year follow-up period, a quarter of them were not eligible for statin therapy by neither of the two algorithms. This study thus adds to previous evidence that current cardiovascular risk scores and algorithms fail to identify a substantial number of individuals at high cardiovascular risk. ${ }^{14,23-25}$ This illustrates the paradox that at a population level many ASCVDs occur in people assumed to be at low cardiovascular risk, ${ }^{10,25}$ simply because they are much more numerous. This also highlights the need to study alternative cardiovascular prevention strategies by integrating complementary approaches (for example, genome-wide polygenic genetic risk scores) ${ }^{26}$ or additional risk markers, such as coronary artery calcium score or lipoprotein(a) levels. ${ }^{10,18,19,25,27}$

Our study has several limitations. First there was a relatively small number of certain incident ASCVDs, such as cardiovascular deaths. This could have limited the precision of some of our analyses, especially the risk prediction models analysis. Nevertheless, the algorithms analysis included 370 events, which is comparable to other studies. ${ }^{28}$ Second, population-based studies may be affected by a 'healthy volunteer' selection bias, ${ }^{29}$ which could have reduced our ability to capture actual cardiovascular risk in the Swiss population. However, the cardiovascular event rate was comparable to previous studies conducted in similar settings in other European cohorts. ${ }^{28,30}$ Third, our study was purely observational and it is possible that a more intensive preventive strategy would have translated into a larger reduction of ASCVD. Fourth, our findings are related to the French-speaking part of Switzerland and might not be generalisable to other regions. Nevertheless, the prevalence of cardiovascular risk factors is relatively homogeneous in Switzerland ${ }^{31,32}$ and the incidence of ASCVD in the region where the CoLaus study (that is, Canton de Vaud) was conducted is similar to that in Switzerland. This reasonably allows extrapolating our results to the whole country. ${ }^{33}$ Fifth, peripheral artery disease was not included in the definition of ASCVD. As neither the AGLA nor ESC risk algorithms included this outcome in their original equations, this minimises the risk that its exclusion reduced the predictive performance of the equations.

Our study also has strengths. First, we used the unique population-based cohort with a 10 -year followup for cardiovascular events in Switzerland. Second, ASCVDs were prospectively collected and independently adjudicated according to recent recommendations and definitions, minimising the risk of misclassification.

\section{Conclusion}

Our findings, relying on contemporary and longitudinal data of more than 5500 Swiss individuals, showed that the AGLA and ESC cardiovascular preventive algorithms had similar accuracy to predict ASCVD and that both the AGLA and ESC scores were valid for use in primary prevention of CVD in Switzerland. However, our results confirmed that a significant proportion of individuals developing CVD are not identified as at high risk by current algorithms, highlighting the need for additional approaches to improve the performance of cardiovascular prevention strategies.

\section{Author contribution}

HB contributed to the design of the study, performed statistical analyses, interpreted the results and wrote the first draft of the manuscript. NH performed the statistical analyses, interpreted the results, wrote part of the article and revised the manuscript for important intellectual content. DN contributed to the design of the study, interpreted the results and revised the manuscript for important intellectual content. MM interpreted the results and revised the manuscript for important intellectual content. PMV collected data, contributed to the design of the study, interpreted the results and revised the manuscript for important intellectual content. JV conceived the original idea of the study, collected data, performed statistical analyses, interpreted the results and revised the manuscript for important intellectual content. JV had full access to the data and is the guarantor of the study. All authors discussed the design and results of the study, and contributed to the final manuscript.

\section{Declaration of conflicting interests}

The author(s) declared no potential conflicts of interest with respect to the research, authorship, and/or publication of this article.

\section{Funding}

The author(s) disclosed receipt of the following financial support for the research, authorship, and/or publication of this article: The CoLaus study was and is supported by research 

grants from GlaxoSmithKline, the Faculty of Biology and Medicine of Lausanne, and the Swiss National Science Foundation (grants 33CSCO-122661, 33CS30-139468, 33CS30-148401 and 33CS30_177535/1). The funding source had no involvement in the study design, data collection, analysis and interpretation, writing of the report, or decision to submit the article for publication. HB received financial support from the Swiss Academy of Medical Sciences (SAMS) and Bangerter Foundation through the Young Talents in Clinical Research grant 2019 (grant 02/08). The Bangerter Foundation has no financial interest in the results of the study. DN received financial support from the Swiss Heart Foundation.

\section{Previous presentations of intermediate results}

- 04.2019: EuroPrevent 2019, Lisbon (ESC Preventive Cardiology Congress)

- 06.2019: Swiss Society of General Internal Medicine Congress 2019

\section{References}

1. Global Burden of Disease. Global, regional, and national age-sex specific mortality for 264 causes of death, 19802016: a systematic analysis for the Global Burden of Disease Study 2016. Lancet 2017; 390: 1151-1210.

2. Kessler C, Biedermann A, Junker T, et al. National strategy for cardiovascular diseases, stroke and diabetes 20172024. CardioVasc Suisse 2016. https://jimdo-storage. global.ssl.fastly.net/file/0ea06388-fdde-4899-94a82d43ec23be53/National_Strategy_2017-2024.pdf (accessed 31 January 2020).

3. Federal Statistical Office. Death and its main causes in Switzerland, 2016. 2019. https://www.bfs.admin.ch/bfs/en/ home/statistics/health/state-health/mortality-causes-death. assetdetail.7206482.html (accessed 31 January 2020).

4. Bundesamt für Gesundheit. Studie praüsentiert erstmalige Berechnungen der direkten und indirekten Kosten der wichtigsten nichtuübertragbaren Krankheiten. Nationale Praüventionsprogramme 2014. https:/www.bag.admin.ch/ $\mathrm{dam} / \mathrm{bag} / \mathrm{de} /$ dokumente/npp/ncd/kostenstudie-ncd.pdf. download.pdf/GzD_BU36_Kostenstudie\%20NCD_D.pdf (accessed 31 January 2020).

5. Conroy RM, Pyorala K, Fitzgerald AP, et al. Estimation of ten-year risk of fatal cardiovascular disease in Europe: the SCORE project. Eur Heart $J$ 2003; 24: 987-1003.

6. Assmann G, Cullen P, Schulte H, et al. Simple scoring scheme for calculating the risk of acute coronary events based on the 10-year follow-up of the prospective cardiovascular Munster (PROCAM) study. Circulation 2002; 105: 310-315.

7. Assmann $G$, Schulte $H$, Cullen $P$, et al. Assessing risk of myocardial infarction and stroke: new data from the Prospective Cardiovascular Munster (PROCAM) study. Eur J Clin Invest 2007; 37: 925-932.

8. Cooney MT, Dudina AL, Graham IM, et al. Value and limitations of existing scores for the assessment of cardiovascular risk: a review for clinicians. $J$ Am Coll Cardiol 2009; 54: 1209-1227.
9. Lloyd-Jones DM, Braun LT, Ndumele CE, et al. Use of risk assessment tools to guide decision-making in the primary prevention of atherosclerotic cardiovascular disease. Circulation 2019; 139: 1162-1177.

10. Piepoli MF, Hoes AW, Agewall S, et al. 2016 European Guidelines on cardiovascular disease prevention in clinical practice. Eur Heart J 2016; 23: 2315-2381.

11. Catapano AL, Graham I, De Backer G, et al. 2016 ESC/ EAS Guidelines for the management of dyslipidaemias. Eur Heart J 2016; 37: 2999-3058.

12. Swiss Atherosclerosis Association. 2018 Swiss Atherosclerosis Association (AGLA/GSLA) cardiovascular recommendations. Swiss Atherosclerosis Association 2018. https://www.gsla.ch/atherosclerose/prevention-delatherosclerose/diagnostic-et-valeurs-cibles-lors-de-dyslipidemie (accessed 31 January 2020).

13. Rossello X, Dorresteijn JA, Janssen A, et al. Risk prediction tools in cardiovascular disease prevention. Eur $J$ Prev Cardiol 2019; 26: 1534-1544.

14. Romanens M, Ackermann F, Abay M, et al. Agreement of Swiss-adapted international and European guidelines for the assessment of global vascular risk and for lipid lowering interventions. Cardiovasc Drugs Ther 2009; 23: 249-254.

15. Marques-Vidal $\mathrm{P}$, Rodondi N, Bochud $\mathrm{M}$, et al. Predictive accuracy and usefulness of calibration of the ESC SCORE in Switzerland. Eur J Cardiov Prev Rehabil 2008; 15: 402-408.

16. Firmann M, Mayor V, Vidal PM, et al. The CoLaus study: a population-based study to investigate the epidemiology and genetic determinants of cardiovascular risk factors and metabolic syndrome. BMC Cardiovasc Disord 2008; 8: 6.

17. Pennells L, Kaptoge S, Wood A, et al. Equalization of four cardiovascular risk algorithms after systematic recalibration: individual-participant meta-analysis of 86 prospective studies. Eur Heart J 2019; 40: 621-631.

18. Grundy SM, Stone NJ, Bailey AL, et al. 2018 AHA/ ACC/AACVPR/AAPA/ABC/ACPM/ADA/AGS/

APhA/ASPC/NLA/PCNA Guideline on the management of blood cholesterol. Circulation 2019; 139: 1082-1143.

19. Arnett DK, Blumenthal RS, Albert MA, et al. 2019 ACC/AHA Guideline on the primary prevention of cardiovascular disease: a report of the American College of Cardiology/American Heart Association Task Force on Clinical Practice Guidelines. Circulation 2019; 140: 596-646.

20. Wilkins EWL, Wickramasinghe KBP, Leal J, et al. European Cardiovascular Disease Statistics 2017. European Heart Network 2017. http://www.ehnheart. org/cvd-statistics/cvd-statistics-2017.html (accessed 31 January 2020).

21. Timmis A, Townsend N, Gale C, et al. European Society of Cardiology: cardiovascular disease statistics 2017. Eur Heart J 2018; 39: 508-577.

22. Siontis GC, Tzoulaki I, Siontis KC, et al. Comparisons of established risk prediction models for cardiovascular disease: systematic review. BMJ 2012; 344: 3318. 

23. Selby K, Nanchen D, Auer R, et al. Low statin use in adults hospitalized with acute coronary syndrome. Prev Med 2015; 77: 131-136.

24. Romanens M, Mortensen MB, Sudano I, et al. Extensive carotid atherosclerosis and the diagnostic accuracy of coronary risk calculators. Prev Med Rep 2017; 6: 182-186.

25. Mortensen MB, Sivesgaard K, Jensen HK, et al. Traditional SCORE-based health check fails to identify individuals who develop acute myocardial infarction. Dan Med J 2013; 60: 4629.

26. Khera AV, Chaffin M, Aragam KG, et al. Genome-wide polygenic scores for common diseases identify individuals with risk equivalent to monogenic mutations. Nat Genet 2018; 50: 1219-1224.

27. Berry JD, Dyer A, Cai X, et al. Lifetime risks of cardiovascular disease. New Engl J Med 2012; 366: 321-329.

28. Kavousi M, Leening MJ, Nanchen D, et al. Comparison of application of the ACC/AHA guidelines, Adult Treatment Panel III guidelines, and European Society of Cardiology guidelines for cardiovascular disease prevention in a European cohort. JAMA 2014; 311: 1416-1423.

29. Fry A, Littlejohns TJ, Sudlow C, et al. Comparison of sociodemographic and health-related characteristics of UK biobank participants with those of the general population. Am J Epidemiol 2017; 186: 1026-1034.

30. de Las Heras Gala T, Geisel MH, Peters A, et al. Recalibration of the ACC/AHA risk score in two population-based German cohorts. PLoS One 2016; 11: 0164688.

31. Marques-Vidal P and Paccaud F. Regional differences in self-reported screening, prevalence and management of cardiovascular risk factors in Switzerland. BMC Public Health 2012; 12: 246.

32. Romanens M, Szucs T, Sudano I, et al. Agreement of PROCAM and SCORE to assess cardiovascular risk in two different low risk European populations. Prev Med Rep 2019; 13: 113-117.

33. Swiss Health Observatory. https://www.obsan.admin.ch// fr/indicateurs/infarctus-du-myocarde (accessed 31 January 2020). 